\title{
Does Pretreatment with a Tumor Necrosis Factor Alpha-inhibitor Improve the Outcome After Ischemic Cerebral Infarction? A Case Report
}

\author{
Konstantinos Dimitriadis ${ }^{1}$, Michael Wenzel ${ }^{1}$, Grete Buchholz ${ }^{1}$, Andreas Straube ${ }^{1}$ \\ 1. Department of Neurology, University Hospital, Ludwig Maximilian University of Munich, Munich, DEU
}

Corresponding author: Konstantinos Dimitriadis, konstantin.dimitriadis@med.uni-muenchen.de

\begin{abstract}
Tumor necrosis factor- $\alpha$ (TNF $\alpha$ ) plays a major role in inflammatory and vascular processes after cerebral ischemia. TNFa-Inhibitors have, on the one hand, been associated with thromboembolic events; on the other hand, they may prevent brain edema after stroke or injury. Here, we report on a 38-year old Caucasian male with a history of Crohn's disease, treated with adalimumab, who presented without brain edema and only minor sequelae after a major ischemic stroke. This case report illustrates two interesting aspects: 1) the treatment with adalimumab could, in that case, be the etiology for the thromboembolic event; and (2) pretreatment with this TNFa-Inhibitor was the most likely reason why the formation of brain edema was suppressed.
\end{abstract}

Categories: Neurology

Keywords: stroke, tnf $\alpha$-inhibitors, blood brain barrier, brain edema

\section{Introduction}

Tumor necrosis factor- $\alpha$ (TNF $\alpha$ ) is involved in blood-brain barrier (BBB) damage and inflammatory as well as vascular responses after brain ischemia. Mechanisms like the expression of tissue factor, the expression of adhesion molecules for leukocytes, and the activation of matrix metalloproteinases (MMPs) lead to bloodbrain barrier disruption and edema [1]. Moreover, the upregulation of TNF $\alpha$ receptor-1 after cerebral ischemia is known to induce apoptosis [2]. TNF $\alpha$-Inhibitors have rarely been associated with thromboembolic events (TEs) [3-4]. Animal studies suggest that the inhibition of TNF $\alpha$ diminishes brain damage after injury $[1,5]$. We report on a young patient, with a history of Crohn's disease (CD) treated with adalimumab, who presented without cerebral edema and minor neurological sequelae after a major stroke.

\section{Case Presentation}

Received 10/01/2017 Review began 10/17/2017 Review ended 11/29/2018 Published 02/19/2019

() Copyright 2019

Dimitriadis et al. This is an open access article distributed under the terms of the Creative Commons Attribution License CC-BY 3.0., which permits unrestricted use, distribution, and reproduction in any medium, provided the original author and source are credited.
A 38-year old Caucasian male patient with a history of CD (with hemicolectomy four years ago) was admitted to the emergency room after an acute onset of singultus, dysarthria, and severe left-sided sensory motor hemiparesis (NIHSS 15). A head computed tomography (CT) scan revealed an occlusion of the right middle cerebral artery (MCA, M1-section) with a perfusion deficit of the complete territory and a partial mismatch in this area. The occluded MCA was re-opened by combining intravenous thrombolysis (74 mg rtPA) and local mechanical revascularization $165 \mathrm{~min}$ after symptom onset. Twelve hours later, the patient surprisingly presented with only a discrete left-sided hemiparesis without hypesthesia and mild dysarthria. Despite the clinical course, a follow-up CT revealed a large infarction comprising two-thirds of the right MCA territory with a slight $3 \mathrm{~mm}$ midline shift. Additional magnetic resonance imaging (MRI) scans (Days 2 and 8), however, were not suggestive of significant cerebral edema (Figure 1). 


\section{Cureus}

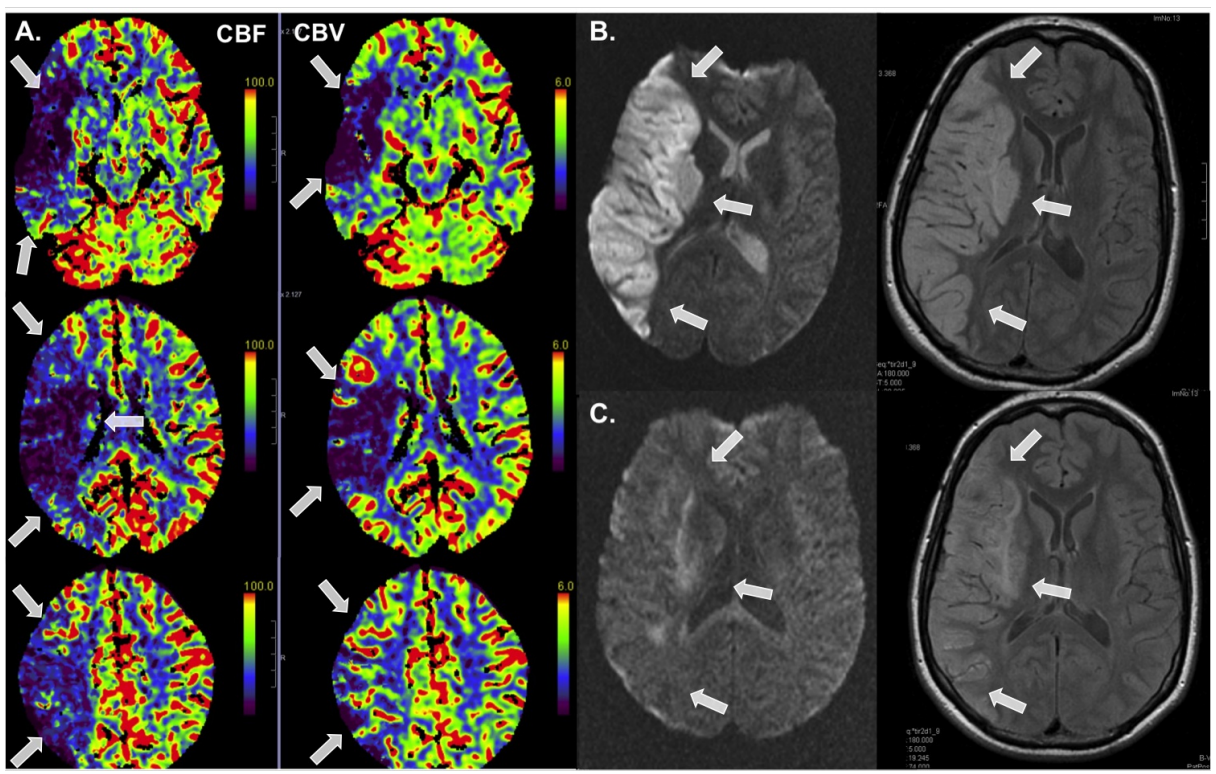

\section{FIGURE 1: CT and MRI Scans}

A: Initial computed tomography (CT) perfusion (cerebral blood flow (left) and cerebral blood volume (right)) showing a large perfusion deficit in the right middle cerebral artery (MCA) area with a partial match. B and C: cranial magnetic resonance imaging (MRI, diffusion and flair weighted) two and eight days after the stroke. There is nearly no perilesional edema.

Duplex sonography, 24h-ECG, echocardiography, as well as laboratory and genetic testing for hypercoagulability and vasculitis were unrevealing. There was a history of smoking (18PY). Adalimumab had been started 3Mo prior to admission. The drug concentration in serum on admission was $29.83 \mu \mathrm{g} / \mathrm{ml}$ (reference $2.0-33.0 \mu \mathrm{g} / \mathrm{ml}$ ). Adalimumab therapy was discontinued after the ischemic episode. The patient was discharged with an NIHSS of 1 . Three months later the patient showed no motor or sensory deficits and resumed his employment.

\section{Discussion}

The findings of this case can be discussed along two lines.

First, it is somewhat unusual that a healthy young subject without any cardiac precondition develops an MCA occlusion. Therefore, it is necessary to discuss if CD itself or its treatment are of pathophysiological relevance in this context. An association of adalimumab treatment and cerebral ischemia has not been described yet. Nevertheless, TEs have been observed in about $4.5 \%$ of patients treated with TNF $\alpha$ antagonists [3-4,6]. Our patient was on adalimumab only for $3 \mathrm{Mo}$, without concomitantly receiving corticosteroids and/or methotrexate and/or cyclooxygenase-2 (COX-2)-selective inhibitors, no antiadalimumab, anti-dsDNA, anti-phospholipid, or anti- $\beta(2)$-glycoprotein antibodies could be detected.

Eventually, we considered chronic intestinal inflammation due to $\mathrm{CD}$ as a potential risk factor for TE. Our patient, however, had been in excellent condition during the three months prior to the infarction, which is why a direct relation seems unlikely.

Secondly, and more remarkably, was the clinical course of the patient. MCA infarctions as expansive as indicated in the MRI images of our patient are usually followed by severe cerebral edema requiring craniectomy. To this date, cerebral infarction size is the major determinant for the probability of cerebral edema [7]. Could it be that the pretreatment with adalimumab prevented cerebral edema in our patient? A rapid increase of TNF $\alpha$-levels after ischemia was seen, promoting pro-inflammatory capillary endothelial cell responses [8]. Moreover, cerebral ischemia leads to an upregulation of TNF $\alpha$ receptor- 1 with consecutive apoptosis [1]. Since adalimumab blocks the interaction of TNF $\alpha$ with cell surface receptors by binding the TNF $\alpha$-molecule, a protective effect can be assumed. As early as in 1994, Feuerstein discussed the neuroprotective effect of TNF $\alpha$-inhibition after brain ischemia [8]. In a rat model, the inhibition of TNF $\alpha$ formation $15 \mathrm{~min}$ prior and even $60 \mathrm{~min}$ after MCA occlusion significantly reduced the infarction size and the clinical deficits without reporting on cerebral edema [9]. King et al. showed that the TNF $\alpha$-inhibitor R7050 significantly reduces BBB disruption, which attenuates edema development after intracerebral hemorrhage and improves neurological outcomes [10]. Hosomi et al. showed that TNF $\alpha$ neutralizing mouse antibodies could, at the same time, reduce the MMPs upregulation after ischemic stroke and reduce cerebral 


\section{Conclusions}

In summary, we present a young patient with a large MCA ischemia of unknown etiology, with a remarkably good clinical course and nearly no cerebral edema. Pretreatment with the TNF $\alpha$-inhibitor adalimumab might have led to the inhibition of cerebral edema formation.

\section{Additional Information}

\section{Disclosures}

Human subjects: Consent was obtained by all participants in this study. Conflicts of interest: In compliance with the ICMJE uniform disclosure form, all authors declare the following: Payment/services info: All authors have declared that no financial support was received from any organization for the submitted work. Financial relationships: All authors have declared that they have no financial relationships at present or within the previous three years with any organizations that might have an interest in the submitted work. Other relationships: All authors have declared that there are no other relationships or activities that could appear to have influenced the submitted work.

\section{References}

1. Hsu H, Shu HB, Pan MG, Goeddel DV: TRADDTRAF2 and TRADD-FADD interactions define two distinct TNF receptor 1 signal transduction pathways. Cell. 1996, 84:299-308. 10.1016/S0092-8674(00)80984-8

2. Hosomi N, Ban CR, Naya T, Takahashi T, Guo P, Song XYR, Kohno M: Tumor necrosis factor-alpha neutralization reduced cerebral edema through inhibition of matrix metalloproteinase production after transient focal cerebral ischemia. J Cereb Blood Flow Metab. 2005, 25:959-967. 10.1038/sj.jcbfm.9600086

3. Korswagen LA, Bartelds GM, Krieckaert CL, et al.: Venous and arterial thromboembolic events in adalimumab-treated patients with antiadalimumab antibodies: a case series and cohort study. Arthritis Rheum. 2011, 63:877-883. 10.1002/art.30209

4. Masson PL: Thromboembolic events and anti-tumor necrosis factor therapies. Int Immunopharmacol. 2011, 14:444-445. 10.1016/j.intimp.2012.08.018

5. Liu T, Clark RK, McDonnell PC, Young PR, White RF, Barone FC, Feuerstein GZ: Tumor necrosis factor-alpha expression in ischemic neurons. Stroke. 1994, 25:1481-1488.

6. Petitpain N, Gambier N, Wahl D, Chary-Valckenaere I, Loeuille Damien, Gillet P: Arterial and venous thromboembolic events during anti-TNF therapy: a study of 85 spontaneous reports in the period 20002006. Biomed Mater Eng. 2009, 19:355-364. 10.3233/BME-2009-0600

7. Hofmeijer J, Algra A, Kappelle LJ, van der Worp HB: Predictors of life-threatening brain edema in middle cerebral artery infarction. Cerebrovasc Dis. 2008, 25:176-184. 10.1159/000113736

8. Feuerstein GZ, Liu T, Barone FC: Cytokines, inflammation, and brain injury: role of tumor necrosis factoralpha. Cerebrovasc Brain Metab Rev. 1994, 6:341-360.

9. Wang X, Feuerstein GZ, Xu L, et al.: Inhibition of tumor necrosis factor-alpha-converting enzyme by a selective antagonist protects brain from focal ischemic injury in rats. Mol Pharmacol. 2004, 65:890-896. 10.1124/mol.65.4.890

10. King MD, Alleyne CH Jr, Dhandapani KM: TNF-alpha receptor antagonist, R-7050, improves neurological outcomes following intracerebral hemorrhage in mice. Neurosci Lett. 2013, 542:92-96. 10.1016/j.neulet.2013.02.05 